\title{
국제개발협력사업 통합평가 실시와 향후 과제
}

\author{
김태은 $\mathrm{ODA}$ 교육원 기획처 과장
}

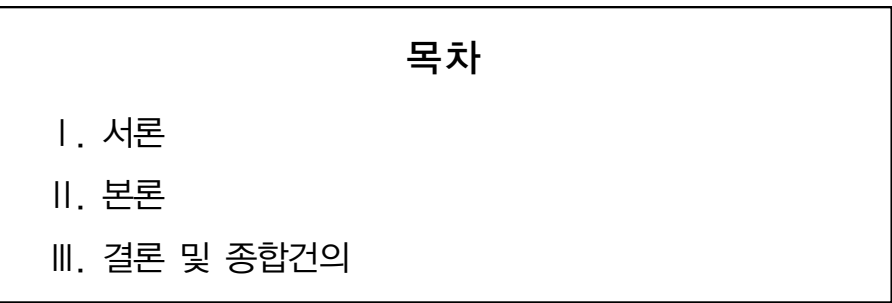

\section{I. 서론}

$\mathrm{OECD} / \mathrm{DAC}$ 가입과 함께 우리 정부는 국제사회에 공약한 ODA 확대 계획(2015년까지 GNI 대비 $0.25 \%)$ 을 추진하는 동시에 원조 체제 개선을 통한 원조 효과성 증대 과제 또한 안게 되었다. 2010년 초 공포된 국제개발협력기본법을 비롯, 국무총리실이 2009년 ODA 선진화 과제로 선정하 여 추진 중인 '국제개발협력사업 통합평가체제 구축' 'ODA 기본계획과 통합국별지원전략 수립', ‘비구속성 원조비율 제고' 등은 모두 원조효과성 제고를 위한 우리 정부의 노력이라 할 수 있다.

이 중 '국제개발협력사업 통합평가(이하 '통합평가')'란 분산된 원조기관별 평가체제를 포괄하는 일 관된 통합평가체제를 구축하여 국제개발협력위원회를 중심으로 $\mathrm{ODA}$ 전반에 대한 평가를 실시한 다는 것이다. 이는 그간 다양하게 논의되어온 국제개발협력 이슈에서 다소 소외되었던 평가의 영 역을 $\mathrm{ODA}$ 개선 주요 과제에 포함시킴으로써, 개발협력사업 평가의 의의와 중요성을 인식시키는 계기가 되었다는 점에서 주목할 만한 사안이다.

통합평가 추진을 위해 국제개발협력위원회는 2009년 통합평가소위원회를 구성하여 '통합평가지침' 
과 '통합평가 매뉴얼'을 마련하였다. 정부는 2010년 동 지침 및 매뉴얼에 따라 시범통합평가를 실 시 중이며, 시범통합평가의 교훈을 반영하여 2011년부터 본격적인 통합평가를 실시할 계획이다.

통합평가와 그 결과는 $\mathrm{ODA}$ 를 수행중인 다양한 부처 및 기관의 $\mathrm{ODA}$ 평가 업무는 물론, 사업계획 이나 추진 과정에도 직간접적인 영향을 미칠 것으로 보여 진다. 본고에서는 이러한 통합평의 주요 내용과 추진 체계를 살펴보고 통합평가의 의의와 효율적인 통합평가 실시를 위해 KOICA 등 관계 자가 고려해야할 현안에 대해 살펴보기로 한다.

\section{II. 본론}

\section{1. 국제개발협력사업 통합평가 실시 배경과 주요 추진 경위}

국제개발협력위원회의 통합평가 실시는 첫째, $\mathrm{OECD} / \mathrm{DAC}$ 의 권고와 둘째, 한국 $\mathrm{ODA}$ 정책 전반에 대 한 점검을 통해 바람직한 $\mathrm{ODA}$ 정책을 기여하겠다는 우리 정부의 의지에 따른 것이라 할 수 있다.

첫째, 통합평가 실시는 $\mathrm{DAC}$ 의 한국 $\mathrm{ODA}$ 평가에 대한 제언에 근거한다. 2008년 $\mathrm{DAC}$ 특별검토단 은 한국에 대한 특별검토보고서(DAC Special Review of Korea)를 통해 한국 ODA의 분절성 문 제를 지적하는 동시에 몇 가지 권고사항을 제시하는데, 그 중 하나가 바로 '국제 기준에 부합하는 독립적 평가 체제' 강화이다. 동 보고서는 한국 ODA가 프로젝트 모니터링·평가의 개선, 평가결과 의 반영 및 공개를 통해 효과를 볼 수 있다고 언급하고 있는데, 이러한 제언은 모든 원조수행기관 에 공통 적용 가능한 평가가이드라인이 부재하고 평가의 독립성과 평가결과 반영이 제도적으로 강 하게 뒷받침되지 않고 있다는 관찰에 따른 것이라 하겠다.

둘째, 통합평가는 분산 실시되는 한국 $\mathrm{ODA}$ 를 전반적으로 점검하여 바람직한 $\mathrm{ODA}$ 정책을 위한 제언을 도출하기 위한 것이다. 한국 $\mathrm{ODA}$ 의 효율성 제고를 위해 분산된 수행기관을 일원화하여 원 조 분절(fragmentation)을 최소화해야 한다는 의견은 오래 전부터 있어 왔으나, 관련 부처간 입장 차이 등으로 원조체제 일원화는 실질적인 결실을 맺지 못하여 왔다. 통합평가는 이러한 한국원조 의 일원화 실패를 보완하고 그 문제점을 최소화하기 위한 차선책 중 하나라 할 수 있다.

즉, 국제개발협력위원회가 부처간 이해관계를 최대한 배제한 총괄적 입장에서 각기 다른 목적과 방식으로 추진되는 우리 $\mathrm{ODA}$ 사업을 '평가'라는 방식을 통해 살펴보겠다는 것, 이를 통해 원조 정 
책 일관성을 제고하고 중복을 방지하는 등 원조효과성 제고를 위한 제언을 도출해 보자는 것이 통 합평가의 취지인 것이다.

이러한 취지에 따라 2009.5월 제5차 국제개발협력위원회가 통합평가를 실시를 결정하고 그해 7월 국제개발협력위원회 산하 통합평가소위원회1)를 구성하였으며, 동 소위원회는 $\mathrm{ODA}$ 사업추진절차 정비(10월)를 시작으로 통합평가지침(11월)과 통합평가매뉴얼(12월)을 제정하여 2010년 현재 추진 중인 시범통합평가의 바탕이 되는 체제를 구축한 것이다. 그럼 통합평가의 주요 내용과 운용 시스 템을 알아보도록 하자.

\section{2. 통합평가 주요 내용 및 시행 체제}

1) 통합평가 주요 내용과 운용 체제의 구성

'통합평가지침'은 국제개발협력사업 평가의 정의를 밝힌 후 통합평가의 원칙 및 기준, 평가의 종류 와 통합평가 관련기관 및 그들의 주요 업무를 규정하고 있다. 지침은 국제개발협력사업 평가의 일 반적 정의를 준용하고 있으며, 통합평가의 원칙과 기준 역시 DAC 및 $\mathrm{KOICA}$ 개발협력사업 가이 드라인과 크게 다르지 않다. 통합평가를 통해 국제개발협력사업 전반을 점검하여 그 성과를 측정 하며, 이는 공정성, 독립성, 신뢰성, 유용성, 파트너십 원칙하에 DAC 5 대 평가 기준인 적절성, 효 율성, 효과성, 파급효과, 지속가능성에 따라 추진되는 것이다.

〈통합지침 및 매뉴얼의 평가 원칙, 기준, 종류〉

\begin{tabular}{|l|}
\multicolumn{1}{|c|}{ 평가의 정의 } \\
\hline $\begin{array}{l}\text { 진행/완료된 } \\
\text { 사업의 } \\
\text { 계획-실행-결과를 } \\
\text { 분석, 성과를 } \\
\text { 측정하는 것 }\end{array}$ \\
\hline
\end{tabular}

\begin{tabular}{|l|l|}
\hline \multicolumn{2}{|c|}{ 통합평가 } \\
\hline \multicolumn{1}{|c|}{ 원칙(Principle) } & \multicolumn{1}{c|}{ 기준(Criteria) } \\
\hline - 공정성(Impartiality) & - 적합성(Relevance) \\
- 독립성(Independence) & - 효과성(Effectiveness) \\
- 신뢰성(Credibility) & - 효율성(Efficiency) \\
- 유용성(Usefulness) & - 파급효과(Impact) \\
- 파트너십(Partnership) & - 지속가능성(Sustainability) \\
\hline
\end{tabular}

평가의 종류

정책/전략·국별· 분야별· 형태별. 프로젝트/프로그램 평가

통합평가지침에 따라 실시되는 평가의 종류는 정책/전략·국별·분야별·형태별·프로젝트/프로그램 평가에 이르기까지 다양한데, 다음에서 살펴보겠지만 평가 대상 범위는 다음과 같이 평가실시기관 별로 차이가 있다.

1) 통합평가소위원회는 위원장(국무총리실 국정운영실장)을 포함한 정부 및 민간위원 15 인 이내로 구성됨. 주요 기능은 연 간통합평가계획수립, 통합평가 실시, 사업수행기관 평가활동 심의 등임. 
통합평가와 관련된 기관은 (1) 통합평가를 주관하고 총괄하는 '통합평가소위원회', (2) ODA 사업을 실제 수행하는 '사업수행기관' $\mathrm{KOICA}$, 수출입은행, 교과부, 농림부 등), (3) 사업수행기관 활동을 총괄하는 협조기관(외교부, 기획재정부) 세 부류로 나뉜다. 이 중 평가대상을 선정하여 평가를 추 진하는 주체는 '통합평가소위원회'와 '사업수행기관'이며, 이들은 '평가수행기관'으로 분류된다. 각 관련 기관별 업무는 다음과 같이 구분된다.

\begin{tabular}{|c|c|c|c|}
\hline \multicolumn{2}{|c|}{ 통합평가 관련 기관 } & \multicolumn{2}{|r|}{ 업무 구분 } \\
\hline \multirow{5}{*}{$\begin{array}{l}\text { 평가 } \\
\text { 실시 } \\
\text { 기관 }\end{array}$} & \multirow{3}{*}{$\begin{array}{l}\text { 통합평가 } \\
\text { 소위원회 }\end{array}$} & 정책 및 계획 & $\begin{array}{l}\text { - ODA 전반 평가에 대한 정책, 지침, 매뉴얼 마련 } \\
\text { - 연간통합평가계회 수립 } \\
\text { - 통합평가결과에 대한 연간 피드백계획 수립 }\end{array}$ \\
\hline & & 평가 & $\begin{array}{l}\text { - 국제개발협력 정책 및 전략 평가 } \\
\text { - 중점지원국 대상 국별 평가 } \\
\text { - ODA 기본계획 상 중점과제 추진성과 평가 } \\
\text { - 기타 평가소위가 필요하다고 판단하는 평가 }\end{array}$ \\
\hline & & 심의 & - 사업수행기관 평가계획 및 결과 심의 \\
\hline & \multirow{2}{*}{$\begin{array}{l}\text { 사업수행기관 } \\
\text { (KOICA, 수은, } \\
\text { 교과부 등) }\end{array}$} & 계획 & $\begin{array}{l}\text { - 기관별 연간평가계획 수립 } \\
\text { - 기관별 피드백계획 수립 }\end{array}$ \\
\hline & & 평가 & $\begin{array}{l}\text { - 기관별 정책/전략, 국별, 분야별, 주제별, 형태별 평가 } \\
\text { - 개별 프로그램/프로젝트 평가 }\end{array}$ \\
\hline $\begin{array}{l}\text { 협조 } \\
\text { 기관 }\end{array}$ & $\begin{array}{l}\text { 외교부 } \\
\text { 기재부 }\end{array}$ & 협조 & $\begin{array}{l}\text { - 통합평가소위원회와 사업수행기관간 연락망 } \\
\text { - 기관별 연간평가계획, 평가결과, 피드백계획 취합 }\end{array}$ \\
\hline
\end{tabular}

상기 표에 따르면 '통합평가소위원회'의 가장 큰 특징은 동 위원회가 ODA 전반을 포괄하는 정책 평가나 무유상 통합 국별평가 부터 특정 사업수행기관의 개별사업평가까지 실시 가능한 권한이 있 다는 것과, 사업수행기관의 평가활동 및 결과 전반에 대한 심의기능을 가지는 것이라 할 수 있다.

2) 통합평가체제 운용 절차

통합평가체제는 상기 관련기관이 각자의 역할을 수행함으로써 운용된다 할 수 있으며, 그 절차는 다음과 같다.

〈표 1〉통합평가시스템 운용 절차

\begin{tabular}{|c|c|c|c|c|}
\hline $\begin{array}{c}\text { 연간평가 } \\
\text { 계획수립 } \\
\text { (사업수행기관) }\end{array}$ & $\begin{array}{c}\text { 기관별 연간평가계획 } \\
\text { 취합· 제출 } \\
\text { (협조기관) }\end{array}$ & $\begin{array}{c}\text { 기관별 } \\
\text { 연간평가계획 심의 } \\
\text { (평가소위) }\end{array}$ & $\begin{array}{c}\text { 연간통합평가계획 } \\
\text { 수립· 확정 } \\
\text { (평가소위) }\end{array}$ & $\begin{array}{c}\text { 평가업무 } \\
\text { 수행 } \\
\text { (평가실시기관) }\end{array}$ \\
\hline 1월말 & 2월중 & 2월중 & 2월말 & 연중 \\
\hline $\begin{array}{l}\text { 기관별 평가결과 } \\
\text { 취합·제출 } \\
\text { (협조기관) }\end{array}$ & $\begin{array}{l}\text { 평가결과 } \\
\text { 심의 } \\
\text { (평가소위) }\end{array}$ & $\begin{array}{c}\text { Feedback } \\
\text { 계획 작성 } \\
\text { (사업수행기관) }\end{array}$ & $\begin{array}{l}\text { feedback계획 } \\
\text { 심의· 확정 } \\
\text { (평가소위) }\end{array}$ & $\begin{array}{c}\text { Feedback 계획 } \\
\text { 사업반영 } \\
\text { (사업수행기관) }\end{array}$ \\
\hline
\end{tabular}


상기 절차에 따라 통합평가소위원회가 수립하는 $\mathrm{ODA}$ 연간통합평가계획은 각 사업수행기관별 연 간평가계획을 접수한 후 평가소위원회의 연간통합평가 대상을 종합하여 수립된다. 따라서, 사업수 행기관이 기수립한 자체연간평가계획의 평가대상이 통합평가 대상과 중복되는 경우 사업수행기관 자체연간평가계획 변경이 불가피한 경우가 발생하기도 한다.

각 평가실시기관(소위, 사업수행기관)은 $\mathrm{ODA}$ 연간통합평가계획에 따라 소관 평가를 실시하고 그 평가결과는 차년도 평가결과반영(feedback) 계획으로 확정되어 향후 사업에 반영되도록 되어 있 다. 그리고 사업수행기관의 동 평가결과반영(feedback) 계획 이행 현황은 통합평가소위원회에 의 해 감독된다.

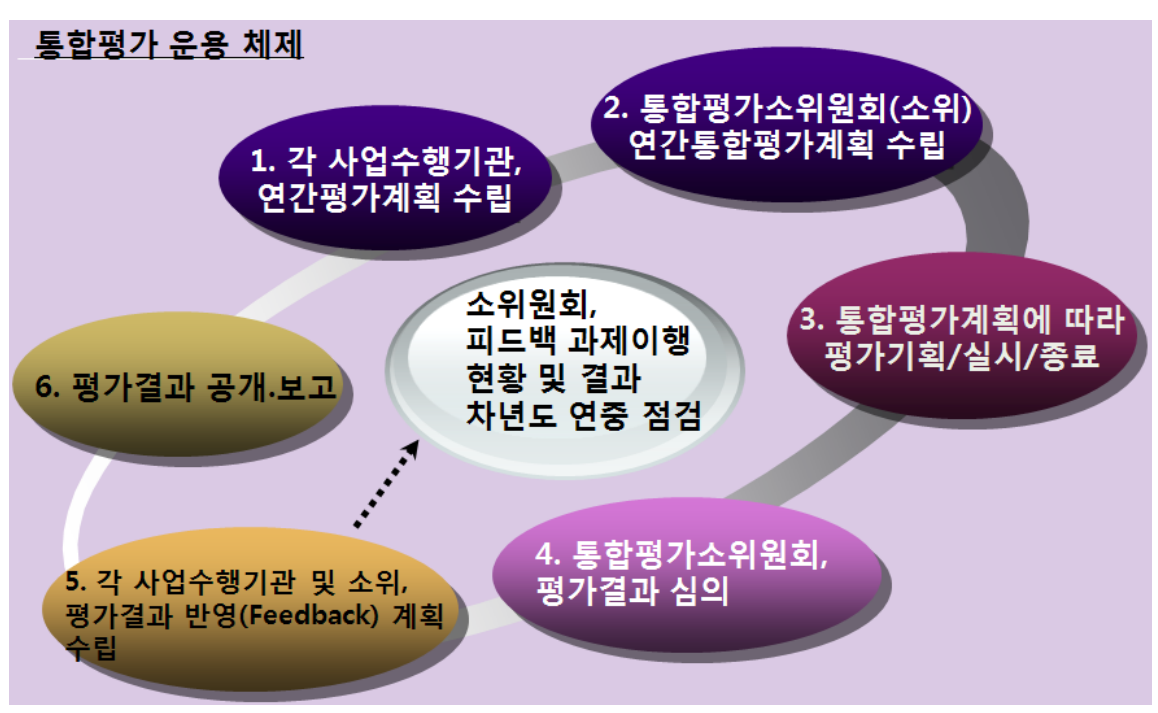




\section{3. 통합평가 실시의 의의}

그럼 지금까지 수행되던 우리 국제개발협력사업 평가와의 차이점을 통해 통합평가의 특징과 의의 를 간단히 살펴보기로 한다. 통합평가 실시로 한국 국제개발협력사업 평가활동은 다음과 같은 다 음과 같은 변화를 겪게 되었다.

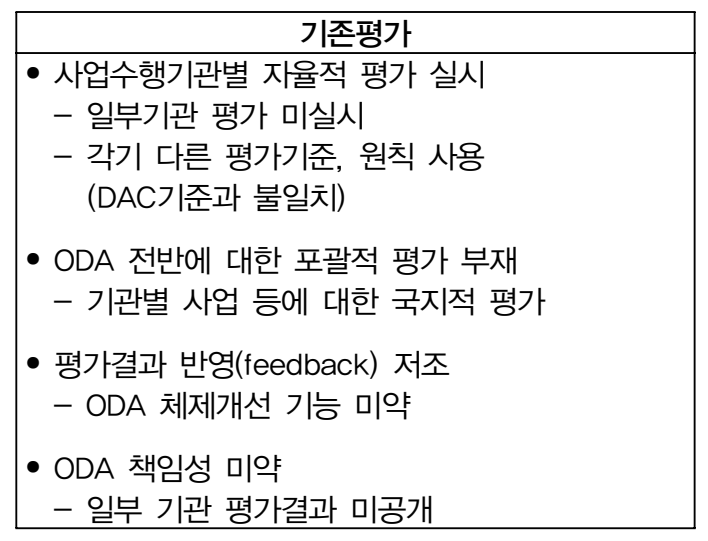

\begin{tabular}{|c|}
\hline 통합평가 \\
\hline - 통합평가소위원회가 평가활동 심사, 감독 \\
- 전사업수행기관의 평가실시 의무화 \\
- 공통의 평가기준, 지침, 매뉴얼 마련 \\
(DAC 기준 준수) \\
- ODA 전반에 대한 포괄적 평가 실시 \\
- 이를 위한 통합평가소위원회 설치 \\
- 모든 기관 Feedback 과제 이행 \\
- 소위, 기관별 과제 및 이행현황 점검 \\
- ODA 책임성 강화 \\
- 평가결과 공개 강화
\end{tabular}

첫째, 통합평가지침과 매뉴얼에 따라 ODA 사업평가가 의무화되고 공통의 평가 기준이 마련되었으 며, 이는 곧 원조의 성과중심관리(Result Based Management)와 평가의 중요성에 대한 인식을 강화하는 기반이 될 것으로 기대된다.

그간 $\mathrm{KOICA}$ 와 $\mathrm{EDCF}$ 를 제외한 대다수의 $\mathrm{ODA}$ 수행기관은 추진 사업에 대한 평가를 생략하거나, 실시한다 하더라도 기관별로 평가기준이나 절차, 종류가 상이하였다. 하지만 새롭게 제정된 '통합 평가지침'은 모든 $\mathrm{ODA}$ 수행기관이 각 기관이 추진한 $\mathrm{ODA}$ 사업을 $\mathrm{DAC} 5$ 대 평가기준에 따라 평가 할 것을 규정하고 있으며, '통합평가매뉴얼'은 평가 절차와 평가매트릭스 작성 등 체계적인 평가 수행을 위한 구체적인 가이드라인을 제시하고 있어 그간 개발협력사업 평가에 대한 노하우가 없었 던 $\mathrm{ODA}$ 수행기관들까지도 개발협력사업 평가에 대한 이해를 제고하게 되었다.

둘째, 통합평가 실시로 $\mathrm{ODA}$ 수행기관 사업 모두에 대한 독립적·포괄적 실시를 가능케 하는 조직 적-제도적 틀이 마련되었다. 통합평가 실시 전 일부 $\mathrm{ODA}$ 수행기관이 $\mathrm{ODA}$ 사업에 대한 평가를 실 시하기는 하였으나, 이러한 평가 활동은 각 기관이 자체적으로 수행한 정책이나 사업으로 국한될 수밖에 없었다. 하지만 통합평가 실시로 인해 민간위원을 포함한 평가소위원회가 설립되었으며, 동 위원회가 통합평가 대상을 선정하여 $\mathrm{ODA}$ 수행기관들의 사업을 포괄적인 관점에서 평가할 수 있게 되었다. 
셋째, 개발협력사업 평가 영역 또한 개별사업평가에서 정책평가, 국별평가, 분야별평가 등으로 다 각화 되었다. 그간 $\mathrm{KOICA}$ 를 제외한 기타 $\mathrm{ODA}$ 수행기관이 개별사업 수준의 평가만을 실시하여온 데 반해, 통합평가지침은 평가의 영역을 국별평가, 주제별평가 등 거시적 관점의 평가로까지 확대 하여 규정하고 있다. 이는 국제사회 개발협력사업 평가 동향을 반영함과 동시에 정책에 기반한 체 계적 원조 수행을 도모하기 위한 전사적 개선과제 도출을 가능케 한다는 점에서 한층 진일보된 조 치라 하겠다.

넷째, 통합평가가 실시되면서 ODA 수행기관의 평가결과 반영(feedback)이 의무화될 전망이다. 평 가의 가장 큰 목적은 현실적 제도개선 과제를 도출하는데 있으며, 동 과제가 향후 정책과 사업추 진에 실질적으로 반영되어 사업수행체제의 실질적인 개선을 가져올 때 평가의 진정한 가치가 발현 되었다 할 수 있다.

DAC의 한국에 대한 특별검토 보고서(2008)가 평가결과반영(feedback)이 제도화되어야 함을 언급 한 것 역시 이러한 맥락에서이다.

지금까지 $\mathrm{KOICA}$ 를 제외한 대부분의 기관이 이를 가능하게 하는 체계적인 평가결과반영(feedback) 절차를 보유하고 있지 않아, 평가를 통한 $\mathrm{ODA}$ 제도개선 기능이 미약하고 평가가 형식에 그치는 경우가 많았던 것이 사실이다. 하지만 통합평가를 통해 각 $\mathrm{ODA}$ 수행기관은 평가를 통한 제언을 향 후 사업에 반영하여야 하며, 통합평가소위원회는 그 이행현황을 점검하여 평가의 제도개선 기능이 점차 강화되어갈 것으로 전망된다.

다섯째, 통합평가소위원회의 통합평가를 비롯하여 각 $\mathrm{ODA}$ 수행기관별로 실시되는 평가결과의 대 국민 공개가 강화될 것으로 예상된다. 이는 원조사업의 대국민 책임성(accountability)을 강화를 위한 것으로, $\mathrm{ODA}$ 수행기관은 예산의 효율성을 극대화하는 전략적 원조, 목표 달성도를 제고하는 성과중심 원조를 추진(Result Based Management)해야 하는 과제를 안게 되었다 하겠다.

\section{2010 시범통합평가 실시 추진 현황}

2010년 9월 현재 지난 3월 통합평가소위원회가 수립한 ODA 시범통합평가계획에 따라 통합평가소 위원회는 '캄보디아 무유상 통합국별평가', '무유상 연계사업 평가', '새마을운동 전수사업 종합평 가' 3 건의 통합평가를, $\mathrm{ODA}$ 사업수행기관은 국별평가와 개별사업평가 등 소관 평가를 추진 중이 다. 시범통합평가는 그 과정상의 교훈을 차년도 통합평가 운영에 반영하기 위해 조기 추진되어 10 월 평가결과가 도출된 계획인데, 금년 초부터 현재까지 추진되고 있는 시범통합평가 과정을 살펴 
보면 다음과 같은 측면에는 개선의 여지가 있어 보인다.

첫째, '통합평가'에 대한 정의와 목적이 불분명하여 '통합평가'라는 용어에 대한 이해가 상이하고 선정된 평가대상이 '통합평가' 본연의 취지에 적합한 대상인지를 판단할 수 있는 근거가 미약해 보인다.

우선 통합평가지침과 매뉴얼 어디에도 '통합평가'의 정의나 목적, 실시 주체에 대한 명확한 설명이 없는데, 이는 '통합평가' 실시 주체가 누구인지, '통합평가'가 평가대상으로 한정되는 의미인지 아 니면 '통합평가'가 이루어지는 시스템 전반을 아우르는 개념인지 등에 대해 각기 다른 해석을 할 여지를 두고 있다.

통합평가지침과 매뉴얼 제정 이후 수립된 ‘2010 ODA 연간통합평가계획'에서는 이러한 개념 구분 을 위해 '평가소위의 통합평가'와 '사업수행기관의 자체평가'로 그 개념을 구분하기는 하였으나, '연간통합평가계획'이 사업수행기관 자체평가 계획까지 포함하고 있어, ‘통합평가’라는 용어가 의미 하는 범위에 대한 의문을 남겨 두고 있다. 사업수행기관의 자체평가 대상 또한 '통합평가' 범주에 들어갈 수 있는지, 그래서 사업수행기관 역시 통합평가 실시 주체라 할 수 있는지 등이 명확하지 않은 것이다.

둘째, 통합평가대상 3 건 모두 그와 관련된 $\mathrm{ODA}$ 상위 정책이나 사업 목표가 뚜렷하지 않아 평가 를 위한 판단의 기준을 수립하는 것부터 어려움이 따랐다.

우리 $\mathrm{ODA}$ 의 대캄보디아 통합국별지원전략이 부재한 상황에서 '캄보디아 통합국별평가'를 실시하 는 것은 쉽지 않다. 대캄보디아 ODA사업 전반의 정책과 전략목표가 없어 목표달성도나 사업수행 의 효율성 등을 파악 가능케 하는 기준점 자체가 모호하기 때문이다. 대개도국 새마을운동전수사 업의 범위나 목적이 무엇인지도 규명되지 않은 상황에서 이루어지는 '새마을운동전수사업 평가' 역시 혼선을 겪을 수밖에 없다. 그리고 무유상 연계가 모든 상황에서 효율적인지, 무유상이 각각 우리 $\mathrm{ODA}$ 정책과 철학 내에서 어떠한 역할을 하는 것이 바람직한지에 대한 합의가 없는 상황에 서 실시되는 '무유상 연계사업 통합평가'는 통합평가의 목적이 과연 무엇인가라는 의문을 가지게 하였다.

셋째, 평가팀에 해당 평가대상과 관련된 전문지식(분야별, 주제별, 국별 등)을 가진 컨설턴트가 포 함되지 않아 평가에 필요한 전문적 의견을 효율적으로 접수하기 어려웠고, 평가소위원회 위원의 업무 부담도 가중된 측면이 있다. 
평가결과의 전문성을 제고하기 위해 평가팀에는 주로 평가대상과 관련된 특정 부문의 전문인력이 포함되는 것이 대부분이다. 하지만 금번 통합평가팀의 경우 평가소위원회와 관련 기관 실무자로만 구성되었다. 별도의 외부 자문 등을 통해 해당 분야 전문 의견을 수렴할 수 있었다 하더라도, 관 련 전문가가 평가팀원으로 구성되어 평가과정 전반에 참여할 경우 평가방향 수립이나 평가대상과 관련한 개념 정립, 체크리스트 작성, 정보수집 등이 훨씬 용이해져, 평가과정의 효율성 또한 제고 할 수 있다는 것을 인식할 필요가 있다.

\section{III. 결론 및 종합건의}

앞서 살펴보았듯 통합평가 실시는 우리 국제개발협력사업 공통의 평가가이드라인 및 매뉴얼을 마 련하는 등 $\mathrm{ODA}$ 사업관리와 평가에 긍정적인 의미를 가진다 하겠다. 통합평가소위원회는 금년 시 범통합평가 실시 경험을 바탕으로 내년부터 본격적인 통합평가를 실시할 예정인데, 당면 과제로 다음과 같은 사항들을 보완한다면 보다 체계적이고 효율적인 통합평가가 가능하리라 판단된다.

첫째, '통합평가지침'에 '통합평가'의 특수한 목적을 규명할 필요가 있다. '통합평가'의 목적은 '평 가'의 일반적인 목적보다 더 세부적이며 특수함에도 불구하고 통합평가지침과 매뉴얼 모두 '통합 평가'의 본래 취지와 목적이 무엇인지를 제시하지 않고 있다. 통합평가매뉴얼이 '제언의 반영과 책 임성 확보'라는 '평가'의 일반적인 목적을 밝히고 있기는 하나, 이는 '평가'가 아닌 '통합평가'가 실 시되는 특수한 배경을 반영하지는 못한다.

왜 통합평가가 필요하였는지, 그래서 통합평가를 통해 무엇을 보고자 하였는지가 통합평가의 목적 을 통해 분명히 규명되어야, 동 목적에 비추어 통합평가 목적 달성에 적합한 평가대상이 선정 되 었는지, 통합평가 취지에 부합하는 평가가 이루어 졌는지, 그래서 통합평가의 목적을 달성하였는 지 등을 판단할 수 있는 근거가 마련된다.

이러한 '통합평가'에 대한 정의와 목적 규명은 $\mathrm{ODA}$ 사업수행기관이 실시하는 평가와 평가소위원 회가 실시하는 평가를 구분하는 기반 또한 마련할 것이며, 이는 결국 통합평가대상 선정부터 제언 도출에 이르기까지 보다 효율적인 통합평가 실시를 가능하게 할 것이다.

둘째, 논리적인 통합평가를 가능케 하는 선결 과제들이 어느 정도 해결되기 전까지는 보다 상위레 벨 정책에 초점을 맞추어 통합평가를 실시할 필요가 있어 보인다. 선결 과제는 통합평가대상에 대 
한 옳고 그름의 가치판단 기준이 될 수 있는 우리 $\mathrm{ODA}$ 사업 전반에 대한 목표와 전략, 통합국별지 원전략 등 $\mathrm{ODA}$ 를 통합적으로 추진할 수 있는 정책적, 제도적 기반을 마련하는 것이라 하겠다.

평가를 하기 위해서는 평가대상을 평가하는 기준이 될 수 있는 사업목표가 있어야 한다. 통합평가 실시 또한 마찬가지다. 통합평가 대상에 대한 평가를 가능케 하는 상위 레벨의 정책 목표와 기준 이 있어야 동 목표 달성 차원에서 통합평가 대상을 평가하고 사업수행체제가 어떻게 변화되어야 하는지 등에 대한 바람직한 제언을 제시할 수 있는데, 아직까지 이러한 정책이 수립되지 않은 상 황이다.

이러한 상황을 고려, 내년 통합평가는 지엽적인 주제 보다는 원조관련 정부정책 및 시스템 등 보 다 근본적인 문제를 탐색 가능한 상위레벨 정책에 초점을 맞추어, 이를 점검 가능한 평가주제를 선정하여 추진하는 것이 효율적이라 판단된다.

셋째, 통합평가소위원회 위원은 '평가'의 실무를 직접 담당하기 보다는 '심의'와 정책자문 역할을 담당하고, 통합평가팀에 평가대상과 관련한 특정분야 전문가나 별도의 평가인력 등을 포함하여 평 가를 추진하는 것이 현실적인 방안으로 보인다.

평가 보고서는 다양한 의견과 자료를 종합적으로 분석하여 객관적 근거를 제시해야하며 이를 위한 평가계획수립, 문헌조사, 현지조사, 인터뷰 등은 상당한 시간과 노력을 요구한다. 통합평가소위원 회 위원의 비상근, 겸직 특성을 고려할 때, 소위원회 위원에게 많은 시간을 필요로 하는 평가의 실무(문헌조사, 현지조사, 보고서 작성 등)까지 요구하는 것은 바람직하지2)않다.

또한 평가소위원회 위원들이 국제개발협력 분야 전반의 정책 및 사업에 대한 전문성을 보유하고 있기는 하나, 평가대상에 따라 국별, 분야별 등 특정 부문의 전문성이 요구되어진다. 평가소위원 회는 평가에 대한 심의와 정책 자문 기능을 담당하고, 실무적인 평가 활동을 위한 컨설턴트 등 별 도 인력을 포함하여 평가팀을 구성한다면 평가의 전문성은 물론 평가과정의 효율성 또한 제고될 것이다.

이를 위해서는 통합평가를 위한 별도의 예산 마련 등 필요한 조치가 선행되어야할 것이며, 통합평 가계획 역시 평가수행 여건을 종합적으로 고려하여 현실적으로 수립되어야할 것이다.

2) 영국 DFID가 평가기능 및 독립성 강화를 위해 설립한 외부위원회인 'Independent Advisory Committee for Development Impact' 역시 평가 계획 및 현황 등에 대한 심의 기능만을 담당하고 있음 
넷째, 각 사업수행기관은 평가결과반영(feedback) 시스템을 구축할 수 있도록 사전 준비해야 한 다. 아직까지 평가결과반영(feedback)을 위한 체계적 절차나 제도를 보유하지 않은 ODA 사업수행 기관이 대부분이다. KOICA는 2008년부터 평가결과반영(feedback) 절차를 수립하여 평가결과가 신규사업 및 정책에 체계적으로 반영되도록 조치하고 있다. 이에 더 나아가 금년부터는 내부 사업 평가시행지침상 평가결과반영(feedback) 과제 이행 부분을 강화하고 부서별 성과관리목표( $\mathrm{MBO})$ 와 피드백과제를 연동시키는 등 관련 규정을 정비함으로써 평가결과반영(feedback) 이행률이 더욱 제 고될 수 있도록 지속 노력하고 있다.

다섯째, 최신 평가동향을 파악하고 평가와 관련된 연구조사를 강화하여 통합평가 지침과 매뉴얼을 지속 보완하여야 한다. DAC 평가네트워크를 중심으로 추진되는 주요 평가 이슈는 물론, 범분야 이슈인 양성평등, 환경 등의 평가기준도 차츰 평가기준으로 포함시켜 사업추진시 동 이슈들이 함 께 고려될 수 있는 기반을 조성해야할 것이다.

여섯째, 평가수행기관에 대한 평가교육을 강화하여 평가의 전문성과 체계성을 제고하고, 관련 전 문가를 육성하여야 한다. 좋은 평가를 위해서는 전문적 평가기술은 물론 평가대상 및 이를 둘러싼 환경 등에 대한 심도 깊은 이해가 필요하나, 아직까지 이러한 자질을 두루 갖춘 전문가가 국내에 많지 않은 실정이다. 질적 평가는 우리 $\mathrm{ODA}$ 수행체제 개선 및 선진 담론 형성과 직결된다는 사실 을 인식하고, 국내 평가인력 양성에 힘써 보다 효율적인 사업 추진 기반을 마련하도록 해야한다.

마지막으로, 통합국별지원전략 수립 등 현재 추진중인 ODA 관련 정책·전략 및 사업계획 수립은 통합평가를 고려하여 추진되어야 하며, $\mathrm{ODA}$ 통합정책 수립, 사업추진 일원화 절차에 따라 통합평 가 체제나 내용 또한 단계적으로 개선되어야 한다.

개발협력 정책과 사업의 기획-실행-평가 사이클은 서로 순환되어 각각 다른 단계에 영향을 미치 는 유기체이다. 각 단계의 유기적 관계를 고려한 체계적 평가가 가능하려면, 정책과 사업이 논리 적으로 연계되어야할 뿐만 아니라, 목표 대비 평가를 가능케 하는 모니터링 가능한 지표가 필요하 다. 이러한 지표는 정책이나 사업 기획단계에서 설정 되어야 성과에 기반한 사업관리가 가능하다. 좋은 기획은 좋은 평가와 연계됨을 이해하고, 향후 개발협력 정책과 사업 기획 단계에서부터 평가 계획과 지표를 고려한다면, 통합평가 실시를 위한 기반이 더욱 공고해질 것이다. 